:abscesses had formed outside the stomach, and a fatal result was brought about by perforation of the sac of the secondary abscess cavity. He cited a case where this had occurred. Whether the valcer was acute or chronic was important. In cases which he had examined post mortem he found that in the area surrounding the ulcer there was a considerable amount of induration, where the gastric wall was enormously thickened, where any attempt at inversion of the wall to close the ulcer, or suture of any kind, would be difficult without invaginating a considerable area of stomach wall. If one had to excise a large indurated area probably cicatricial tissue would not unite in the same way as healthy mucous - membrane. Every moment of delay added to the gravity of the operation. Perforations due to perforative periconitis in typhoid fever could not be classed with such cases, as the ulceration was generally multiple, and although one perforation might be closed by operation, there was no guarantee that there were not other points about to rupture. It was much more difficult to close the stomach wall in a state of induration due to chronic inflammation than to close the intestinal wall.

After remarks from Mr. H. G. CroLy and Dr. A. J. Sмrtr Mr. LeNTAIGNE said he had had two cases recently under his care, in both of which there was absence of liver dulness. In the first case operation was not allowed, and the patient died in two or three days. Post-mortem examination showed a gastric ulcer on the anterior wall of the stomach. The sym'ptoms of the second case were similar, and at the request of the patient, though against the wishes of the parents, the abdomen was opened. However, the perforation could not be found, and was not certainly on the anterior wall. He introduced a gauze drain, and endeavoured to give relief. The patient died in a week. Post-mortem examination showed a perforation on the posterior wall, and quite inaccessible.

Mr. JohN CampBeLL, in reply, said that although the anterior wall was by far the most favourable situation, still, it was possible to deal successfully with a rupture on the posterior - wall at times, as was proved by a late successful case under Dr. Walton Browne, of Belfast. Regarding the likelihood of success, his own case was fortunate in respect to the amount of extravasation, which, he thought, had more to do with success than anything else. The more extravasation, the less chance of success. Probably it was not worth while to operate later than twenty-four hours after perforation. With reference to flushing versus sponging the abdominal cavity, he was in favour of the latter as it was easier for the patient and flushing often diluted and disseminated the material through the cavity. He was against operating in perforation from typhoid nlcers, as the patient was not able to bear a laparotomy. In answer to Mr. Lentaigne, he said that the liver dulness was present three hours after perforation, but had disappeared fourteen hours after perforation.

\section{Hemorrhage as a Complication of Internat} URETHROTOMY.

Mr. T. Mrums read a paper on this subject.

The President had had only one case of severe hæmorrhage after internal urethrotomy. Lately, in cases of tight - strictures, he had performed internal urethrotomy, combined at once with a perineal section. By this means hæmorrhage, if it occurred, could be dealt with immediately. He was against the use of iron solution in connection with a wound win the urinary tract.

Mr. CROLY said that nothing would induce him to perform 'Maissonneuve's operation. He used Syme's and Wheel'house's methods, and never losta case of external urethrotomy. He had never seen troublesome hæmorrhage. External wrethrotomy for a bad stricture, if the kidneys were sound, -was a most successful procedure. If hæmorrhage did occur :after external urethrotomy it was easily controlled.

Mr. Lentalgne had had one case in which severe hæmorsrhage occurred after the operation of internal urethrotomy. THe spoke very strongly in favour of Maissonneuve's operation.

Remarks were also made by Dr. T. E. GordoN, Dr. G. J. ¿Johnston, Dr. R. Lane.Joynt, Mr. E. H. Bennett, and Surgeon-General PotTrR; and Mr. MrLes, in reply to Mr. Bennett, said that he had not intended to convey that strictures were present altogether on the floor of the urethra.
They were sometimes present on the roof, but in the large percentage of cases on the floor, because the antecedent ulcer was on the floor. For years there had been probably no greater advocate for Maisonneuve's operation than himself. it was the only instrument capable of dividing a stricture along the entire length of urethra. He did not agree with Mr. Lentaigne regarding the rectal pressure. If the rectum was inflated with $a$ bag, and the venous flow back from the prostatic plexus obstructed, the hæmorrhage was increased. The operation of perineal section without a guide was diffcult if the urethra was empty; it was not if the urethra was full.

Association of Registered Medioal Women.-The annual meeting of this Association was held on June I4th, at the New Hospital for Women, when the business of the Association was transacted. The Managing Committee for the ensuing year was elected as follows: Mrs. Garrett Anderson, Mrs. Berry, Mrs. Boyd, Miss Chadburn, Miss Cock, Miss Crosfield, Mrs. Keith, Mrs. Scharlieb, Miss Sheppard, Miss Helen Webb. From this number the officers were elected: President: Miss Cock. Vice President and Treasurer: Mrs. Boyd. Secretary and Librarian: Miss Crosfield. In the evening the members dined together at the Midland Grand Hotel, fifty-eight being present.

ERRatUM. - In the report of the meeting of the Clinical Society which appeared in the BRITISH MEDICAL JOURNAL of June 4 th, some remarks Pasteur were erroneously attributed to Dr. Parkes Weber.

\section{REVIEWS,}

Inflammation of thi BLadder and Urinary Fever. Bg C. Manseld Modulin, M.D.Oxon., F.R.C.S., Surgeon to, and Lecturer on Surgery at, the London Hospital. London: H. K. Lewis. 1898. (Demy 8vo, pp. 164. 58.)

THERE has long been need of some authoritative work in the English language dealing with the subject of cystitis from the point of view of modern pathology. In no department of surgery' has there been more laxity and inaccuracy of thought and of action than in this. This small work of Mr. MANSELr Moolnrs is an attempt to supply this deficiency, and to explain, in terms of microbial pathology, some of the more usual forms of cystitis, their causation, and their results. There can be no doubt that the effort is successful. Much good work in this direction has been accomplished abroad, notably by Rovsing and Melchior, the best of which the author has judiciously incorporated in his book. The excellent description of urinary fever by Thorndike, however, appears to have escaped his notice.

The author seems hardly as yet to have convinced himself of the accuracy of some of his own statements : thus, we read in the preface that "inflemmation of the bladder is always due to micro-organisms," and yet in the text we find described "simple cystitis, inflammation of the bladder due to chemical or mechanical irritants in the absence of living organisms." This latter form, as indeed $\mathrm{Mr}$. Moullin himself remarks, is, if it exist at all, a matter merely of acsdemic interest and of no clinical significance or import.

The work consists of twelve chapters, each describing one branch of the subject, as "suppurative cystitis," "the organisms found in the urine in suppurative cystitis," "urinary fever," and so on. In the latter chapter four varieties of urinary fever are described: (I) The occurrence of a single rigor or more rarely of more than one. The urine generally contains the bacillus coli. (2) The prominent feature is profound collapse with or without a rigor, occurring almost invariably after kidney operations. (3) "Catheter fever." (4) Continued fever with rigors often occurring as regularly as attacks of ague. The urine is loaded with micro-organisms: Only the first two can in any way be included under the heading of urinary fever. The third should be described as cystitis and ascending pyelonephritis; the fourth as septic infection.

This classification ignores, and purposely ignores, any knowledge of urinary fever due merely to the excitation of the 